\title{
3,4-and 3,5-disubstituted 2-pyridones using an intermolecular cycloaddition/cycloreversion strategy: toward the synthesis of aristopyridinone $\mathrm{A}$
}

\author{
Maren K. Leibowitz \\ College of William and Mary \\ Ethan S. Winter \\ College of William and Mary \\ Jonathan R. Scheerer \\ College of William and Mary
}

Follow this and additional works at: https://scholarworks.wm.edu/aspubs

\section{Recommended Citation}

Leibowitz, M. K., Winter, E. S., \& Scheerer, J. R. (2015). 3, 4-and 3, 5-disubstituted 2-pyridones using an intermolecular cycloaddition/cycloreversion strategy: toward the synthesis of aristopyridinone $A$. Tetrahedron letters, 56(44), 6069-6072. 


\title{
3,4- and 3,5-disubstituted 2-pyridones using an intermolecular cycloaddition/cycloreversion strategy: toward the synthesis of aristopyridinone $A$
}

\author{
Maren K. Leibowitz, Ethan S. Winter, Jonathan R. Scheerer* \\ Department of Chemistry, The College of William E Mary, PO Box 8795, Williamsburg, VA 23187, USA
}

\section{A R T I C L E I N F O}

\section{Article history:}

Received 13 August 2015

Revised 8 September 2015

Accepted 16 September 2015

Available online 21 September 2015

\section{Keywords:}

2-Pyridone

Cycloaddition/cycloreversion

Alkaloid synthesis

Aristopyridinone

Aristolochia

\begin{abstract}
A B S T R A C T
The intermolecular cycloaddition of pyrazinone precursors with alkyne substrates was evaluated. The resulting regioisomeric [2.2.2]-diketopiperazine alkene cycloadducts were diverted into 2-pyridone products through cycloreversion of the [2.2.2]-bicyclic intermediates. New insights into the regioselectivity of pyrazinone azadiene Diels-Alder reactions as well as cycloreversion reactivity were revealed in this study. Synthetic sequences using this $[4+2] / r[4+2]$ strategy were determined that can produce predominantly the 3,5-disubstituted 2-pyridone alkaloid structures; pyridones featuring the 3,4-substitution pattern are observed as the minor regioisomeric products.
\end{abstract}

(c) 2015 Elsevier Ltd. All rights reserved.
Aristolochia manshuriensis is a vining plant with a history of use in Traditional Chinese Medicine that traces to the 3rd century BCE. ${ }^{1}$ A. manshuriensis was most widely distributed for purported antiinflammatory and diuretic properties, although the most abundant metabolites, aristolochic acids and structurally-related ester and amide derivatives, are highly nephrotoxic and carcinogenic. ${ }^{2}$ Recent efforts have sought to identify constituents in the plant that possess anti-inflammatory activity and evaluate these metabolites for cytotoxicity. ${ }^{3}$ Aristopyridinone $A^{4}$ (1), a 2-pyridone alkaloid that does not share the phenanthrene core of the aristolochic acids, was revealed from renewed isolation efforts, although an insufficient amount was isolated in order to determine if $\mathbf{1}$ possessed anti-inflammatory activity. ${ }^{5}$

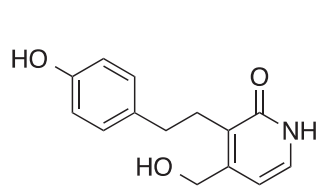

1 Aristopyridinone $\mathrm{A}$
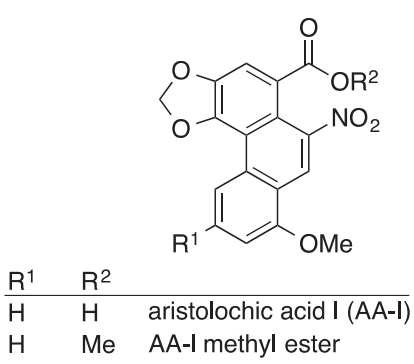

$\mathrm{OH} \quad \mathrm{H} \quad \mathrm{AA}-\mathrm{IVa}$

\footnotetext{
* Corresponding author. Tel.: +1 757221 2551; fax: +1 7572212715.

E-mail address: jrscheerer@wm.edu (J.R. Scheerer).
}

We recently developed a general synthetic method for the construction of 2-pyridone derivatives via cycloaddition of pyrazinone intermediates and subsequent cycloreversion of the intermediate [2.2.2]-diazabicycloalkene cycloadduct. ${ }^{6}$ These preliminary efforts focused primarily on intramolecular pyrazinone Diels-Alder reactions, where cycloaddition regiochemistry was not assessed. We viewed $\mathbf{1}$ as an instructive disubstituted 2-pyridone model in which to explore the extension of this synthetic strategy to include an intermolecular Diels-Alder/retro-Diels-Alder process. The 2pyridone core is a medicinally privileged scaffold and we predicted that a synthesis directed toward $\mathbf{1}$ would provide material to assess the bioactivity and also prove useful in the construction of other 2-pyridone-containing molecules. ${ }^{7}$

Our approach toward pyridone $\mathbf{1}$ is outlined below (Scheme 1). We anticipated that the requisite Diels-Alder precursor could be prepared by aldol condensation of the differentially-protected glycine-derived diketopiperazine ${ }^{8}$ (DKP) 3 with arylacetaldehyde $\mathbf{2}$ followed by alkene isomerization of the exocyclic alkene to give the necessary endocyclic azadiene apparent in pyrazinone 4 . Diels-Alder cycloaddition with a suitable alkyne substrate would afford the regioisomeric intermediate [2.2.2]-bicyclic adducts 5a and $\mathbf{5 b}$. The cycloadducts could deliver the 3,4- and 3,5-disubstituted pyridones $\mathbf{6 a}$ and $\mathbf{6 b}$ following cycloreversion and selective extrusion of one lactam bridge (illustrated as the lactim ether). Final $\mathrm{O}$ - and $\mathrm{N}$-deprotection of the aryl ether and dimethoxybenzyl residues in isomer $\mathbf{6 a}$ as well as any necessary functionalization to reveal the hydroxymethyl at $\mathrm{C} 4$ of the pyridone would complete 


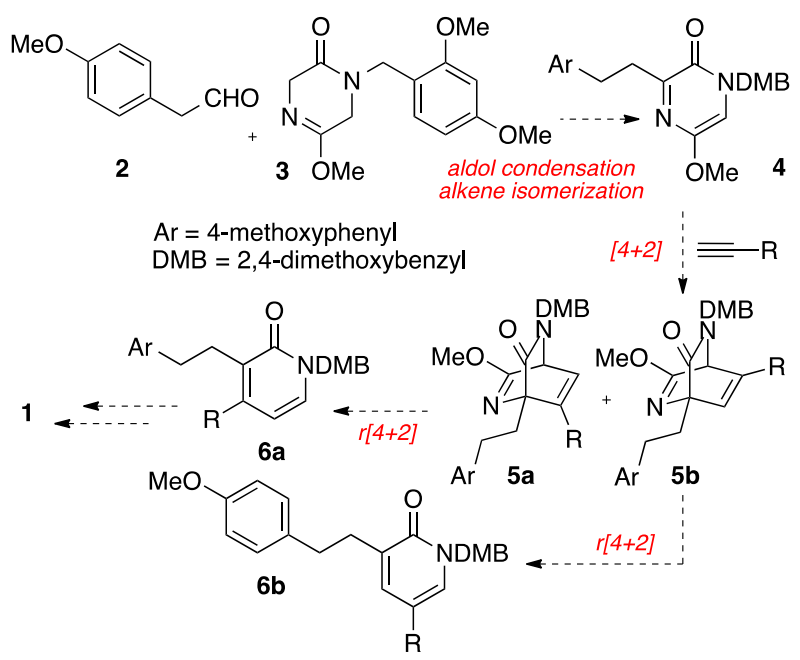

Scheme 1. Synthesis plan toward 3,4- and 3,5-disubstituted 2-pyridones.

aristopyridinone A. At the time we initiated this study, there were insufficient data to reliably predict which regioisomeric cycloadduct $\mathbf{5 a}$ or $\mathbf{5 b}$ would dominate. Because pyrazinones (e.g., 4) are reactive with both electron-rich and electron-deficient dieneophiles, we anticipated that we could explore different electronic properties of the alkyne dieneophile where the substituent would be either an electron-donating or electron withdrawing group. In this way, we envisioned potential control of regioselection in the Diels-Alder event.

In order to validate our general synthetic plan, we first initiated a model sequence starting with DKP $\mathbf{3}$ and benzaldehyde (Scheme 2). The aldol condensation was completed in a three-step operation that involved enolization, aldol addition, acetylation, and elimination of the derived $\beta$-acetoxy derivative with DBU to give $\mathbf{7}$. Based on our experience with aldol condensations with DKP substrates, we expected DKP alkylidene intermediate 7 to isomerize under the basic elimination reaction conditions (DBU) to the endocyclic alkene 8. ${ }^{9}$ We were somewhat surprised that we did not observe pyrazinone $\mathbf{8}$ directly from the elimination reaction. The equilibrium between $\mathbf{7}$ and $\mathbf{8}$ is operational as evidenced by

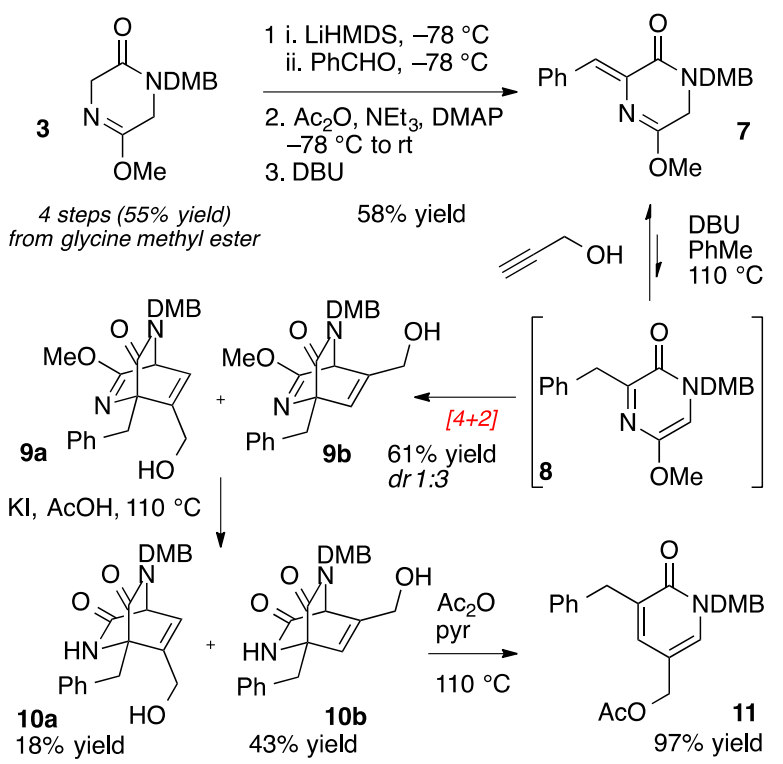

Scheme 2. Pyridone synthesis model study.
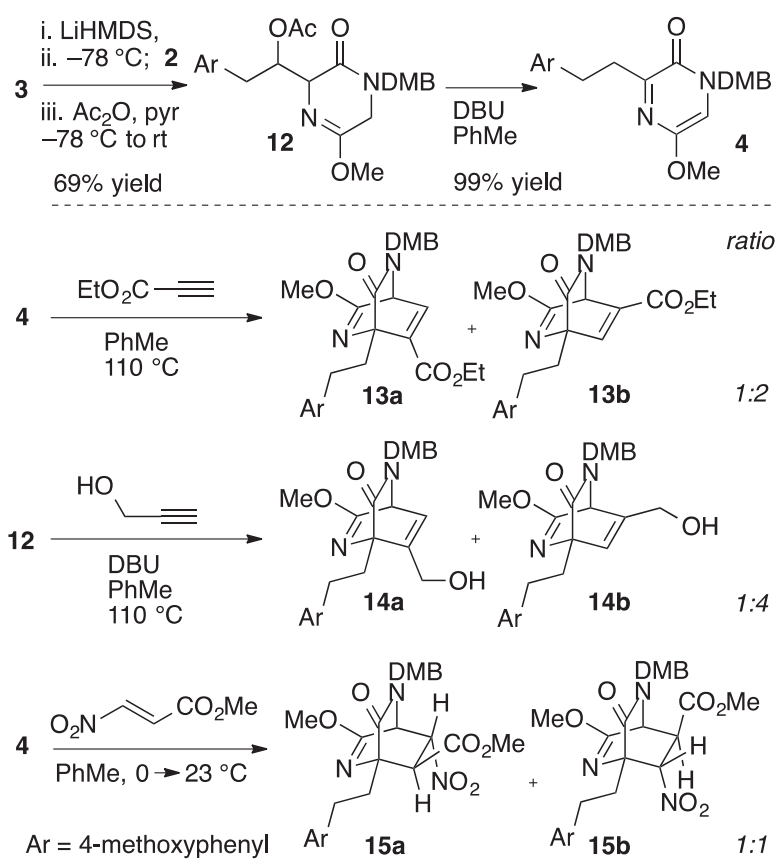

Scheme 3. Preparation and cycloaddition of pyrazinone intermediate.

production of cycloadducts 9a and 9b on heating DKP $\mathbf{7}$ with DBU in the presence of propargyl alcohol. Heating with DBU in the absence of propargyl alcohol returned only starting material DKP 7. We can thus conclude that the exocyclic alkene in $\mathbf{7}$ is thermodynamically more favorable than the isomeric pyrazinone $\mathbf{8}$.

Cycloadducts $9 \mathbf{a}$ and $\mathbf{9 b}$ were produced as an inseparable mixture (ratio 1:3) favoring 9b. Cleavage of the lactim $O$-methyl ether with $\mathrm{KI}$ in $\mathrm{AcOH}\left(110^{\circ} \mathrm{C}\right)$ provided lactams 10a and 10b, which could be separated by chromatography. Lactam activation and cycloreversion were accomplished on major isomer 10b on heating $\left(110^{\circ} \mathrm{C}\right)$ with $\mathrm{Ac}_{2} \mathrm{O}$ and pyridine to afford the 3,5-substituted pyridone 11 (97\% yield). Our initial communication on the cycloreversion of [2.2.2]-diketopiperazine alkene substrates to give 2-pyridone products employed microwave heating (max. temp $\sim 200^{\circ} \mathrm{C}$ ). ${ }^{6}$ The modified thermolysis conditions reported in this Letter are an improvement in efficiency and employ more manageable temperatures for cycloreversion $\left(110^{\circ} \mathrm{C}\right)$.

The synthesis of pyridone $\mathbf{1 1}$ validated our general strategy, although we wanted to determine cycloaddition reaction conditions that would reverse the regioselectivity and ultimately provide access to pyridones with 3,4-substitution as the major product, the structural pattern present in aristopyridinone A (1).

Toward this end, a modified aldol condensation sequence was performed with 4-methoxyphenylacetaldehyde (2) and could deliver pyrazinone $\mathbf{4}$ in one reaction vessel (Scheme 3). Because pyrazinone $\mathbf{4}$ is somewhat oxygen-sensitive and decomposes on silica gel, in practice we found it more convenient to isolate and purify the intermediate $\beta$-acetoxy adduct $\mathbf{1 2}$. As needed, reserves of intermediate $\mathbf{1 2}$ were converted to pyrazinone $\mathbf{4}$ by elimination of the $\beta$-acetoxy residue and alkene isomerization with DBU. The intermediate exocyclic alkene product was not observed in this sequence and the equilibrium appears to favor pyrazinone 4 .

The cycloaddition of pyrazinone $\mathbf{4}$, which was used directly without purification, was explored with three electronically distinct dieneophiles. Using ethyl propiolate, a mixture of cycloadducts 13a and 13b was obtained in a $1: 2$ ratio $(63 \%$ combined yield). In agreement with our model system, cycloaddition of $\mathbf{4}$ with propargyl alcohol afforded adducts $\mathbf{1 4 a}$ and $\mathbf{1 4 b}$ (1:4 ratio, $78 \%$ combined yield). The $\beta$-acetoxy intermediate 12 was used as 
the starting material for this sequence; acetate elimination, isomerization, and Diels-Alder cycloaddition with propargyl alcohol were accomplished in domino fashion in the same reaction vessel.

The dominant regioisomer possessed 3,5-substitution for the cycloaddition with both propiolate and propargyl alcohol. Methyl 2-nitroacrylate can be used as a synthetic equivalent of propiolate that possesses the opposite electronic properties and is often an effective tool in reversing cycloaddition regioselectivity. ${ }^{10}$ In our hands, the nitroacrylate was more reactive and cycloaddition with pyrazinone 4 was achieved near ambient temperatures; however, we observed little influence on regioselection and an approximate $1: 1$ mixture of $\mathbf{1 5 a}$ and $\mathbf{1 5 b}$ was obtained (56\% combined yield).

We decided to move forward toward the cycloreversion with 13a and 13b (1:2 ratio), the cycloadducts derived from ethyl propiolate (Scheme 4). Toward this end, the lactim $O$-methyl ether was cleaved with $\mathrm{KI}$ in $\mathrm{AcOH}\left(110^{\circ} \mathrm{C}\right)$ to give lactams $\mathbf{1 6 a}$ and $\mathbf{1 6 b}$. We were unable to effectively separate isomers by chromatography and the mixture (1:2 ratio) was submitted to the reaction conditions that promote cycloreversion $\left(\mathrm{Ac}_{2} \mathrm{O}\right.$, pyr, $\left.110^{\circ} \mathrm{C}\right)$. Isomers 16a and 16b behaved differently under the reaction conditions and products 19 and 20 were afforded (in 12\% and 64\% yield). The 3,5-disubstituted pyridone $\mathbf{2 0}$ is the result of cycloreversion of $\mathbf{1 6} \mathbf{b}$ via the derived activated intermediate $\mathbf{1 7} \mathbf{b}$. Formation of the 3,4,6-trisubstituted pyridone 19 from $\mathbf{1 6 a}$ can be explained by $\mathrm{N}-\mathrm{C} 3$ bond cleavage, followed by loss of the C6-proton. The divergent reaction pathways for isomers $\mathbf{1 6 a}$ and $\mathbf{1 6 b}$ are intriguing and we see two possible explanations for this differing reactivity.

The observed rearrangement of $\mathbf{1 6 a}$ (in preference to retrograde Diels-Alder) suggests a highly asynchronous transition state for the thermolysis. In isomer $\mathbf{1 6 a}$ the bridgehead proton is doubly activated by both the vinylogous ester at $\mathrm{C} 4$ and the imide extending from $\mathrm{C} 6$. As ionization of the $\mathrm{N}-\mathrm{C} 3$ bond begins, the geometric constraint of the [2.2.2]-bicyclo bridge relaxes and the C6-bridgehead proton becomes aligned for deprotonation. Intermediate 18 illustrates complete ionization of the $\mathrm{N}-\mathrm{C} 3$, although partial ionization may be sufficient to permit deprotonation at C6. If intermediate

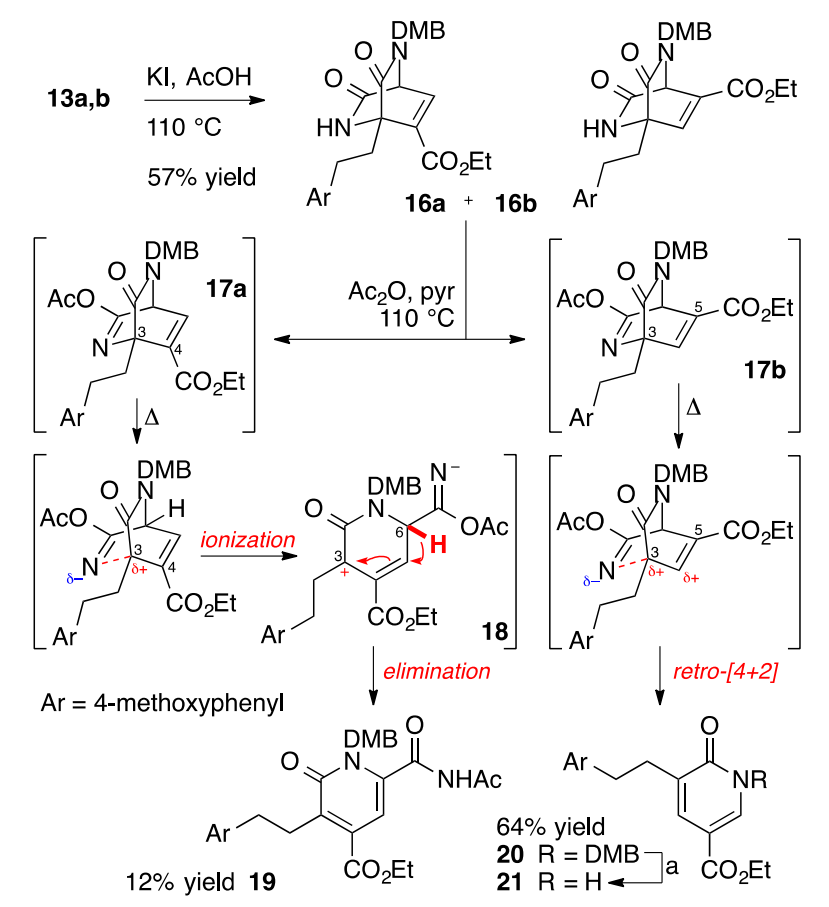

(a) $\mathrm{TFA} / \mathrm{CH}_{2} \mathrm{Cl}_{2}$ (1:2), $\mathrm{Et}_{3} \mathrm{SiH}, 130{ }^{\circ} \mathrm{C}$ micro wave, $30 \mathrm{~min}$ ( $99 \%$ yield)
18 is operational, the thermodynamic acidity of the C6 proton would be very high $(<10 \mathrm{pKa})$ and enolization would be rapid. Alternatively, ionization of $\mathrm{N}-\mathrm{C} 3$ bond in the isomeric intermediate 17b might be destabilized by developing adjacent electropositive charges (from the $\beta$-carbon of the unsaturated ester). This would potentially shift the reaction pathway toward cycloreversion and explain why the 3,5-disubstituted pyridone $\mathbf{2 0}$ is the observed product with isomer $\mathbf{1 7 b}$. The DMB protecting group provides useful protection of the pyridone $\mathrm{N}-\mathrm{H}$ throughout our sequence. We found that the DMB group is most effectively removed under acidic conditions as demonstrated by the conversion of pyridone $\mathbf{2 0}$ into 21 (TFA, $\mathrm{CH}_{2} \mathrm{Cl}_{2}, \mathrm{Et}_{3} \mathrm{SiH}, 130^{\circ} \mathrm{C} \mu \omega, 30 \mathrm{~min}, 99 \%$ yield).

The thermolysis reaction of $\mathbf{1 6 a}$ and $\mathbf{1 6 b}$ revealed that an electron withdrawing group at $\mathrm{C} 4$ of the [2.2.2]-diketopiperazine alkene intermediate (such as $\mathbf{1 6 a}$ ) will not undergo cycloreversion. We performed the analogous sequence starting from cycloadducts 14a and 14b (ca. 1:4 ratio), which bear hydroxymethyl substitution at the alkene (Scheme 5). Cycloreversion of the lactam intermediates derived from 14a and 14b occurred on both isomeric substrates and afforded the 3,4- and 3,5-pyridones 22a and 22b. Separation of the isomers was accomplished after removal of the acetoxy residue $\left(\mathrm{K}_{2} \mathrm{CO}_{3}, \mathrm{MeOH}\right)$ gave products 23a and 23b in $28 \%$ and $53 \%$ isolated yields.

Formation of 23a and 23b demonstrates that cycloreversion is effective with hydroxymethyl (or acetoxymethyl) substitution on the derived intermediate [2.2.2]-diazabicyclic structure. Accordingly, this reaction sequence offers a method to access either 3,4or 3,5-substituted pyridone products from the corresponding regioisomeric [2.2.2]-diazabicyclic cycloadducts. The limitations of this chemistry (at least with the dieneophiles explored in this study) show that construction of 3,5-disubstituted 2-pyridone products is the major product and 3,4-disubstituted products are afforded as minor regioisomeric products. Although intermediate 23a could potentially be converted to aristopyridinone $A(\mathbf{1})$ in a few operations, in order to execute an efficient synthesis an alternative and more selective route toward $\mathbf{1}$ is warranted.

In summary, we have revealed a method to prepare 2-pyridones with a synthetic sequence that intercepts an intermolecular pyrazinone [4+2] cycloaddition, followed by cycloreversion of the derived intermediate [2.2.2]-bicycloalkene adducts. The reaction conditions employed for cycloreversion $\left(\mathrm{Ac}_{2} \mathrm{O}, \mathrm{pyr}, 110^{\circ} \mathrm{C}\right)$ are more expeditious and easier to execute than the conditions previously employed. We gained new insight into both the cycloaddition and cycloreversion operations. In particular, we revealed that propargyl alcohol and propiolate give the same dominant regioisomer for cycloaddition (leading to 3,5-disubstituted pyridones). This result suggests that the regioselectivity in the cycloaddition of pyrazinone intermediates is not especially responsive to the electronic nature of the alkyne dieneophile. We also revealed

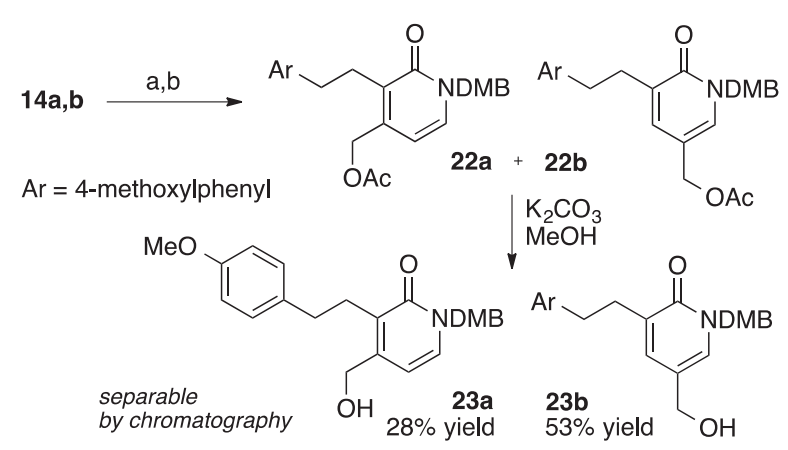

(a) $\mathrm{KI}, \mathrm{AcOH}, 100{ }^{\circ} \mathrm{C}\left(69 \%\right.$ yield); (b) $\mathrm{Ac}_{2} \mathrm{O}$, pyr, $110{ }^{\circ} \mathrm{C}(88 \%$ yield $)$ 
that an electron-withdrawing residue at $\mathrm{C} 4$ of a [2.2.2]-bicycloalkene cycloadduct promotes a rearrangement in preference to extrusion of the lactam bridge (cycloreversion). The chemistry revealed in this synthetic exercise is useful for the construction of both [2.2.2]-diazabicyclic intermediates and 2-pyridone structures, in particular, those structures bearing 3,5-substitution.

\section{Acknowledgment}

The authors acknowledge support from the National Institutes of Health (R15 GM107702 to J.R.S.).

\section{Supplementary data}

Supplementary data associated with this article can be found, in the online version, at http://dx.doi.org/10.1016/j.tetlet.2015.09. 067.

\section{References and notes}

1. Hu, S.-L.; Zhang, H.-Q.; Chan, K.; Mei, Q.-X. Toxicology 2004, 198, 195-201.

2. (a) Mix, D. B.; Guinaudeau, H.; Shamma, M. J. Nat. Prod. 1982, 45, 657-666; (b) Nortier, J. L.; Vanherweghem, J. L. Toxicology 2002, 181, 577-580; (c) Debelle, F.
D.; Vanherweghem, J. L.; Nortier, J. L. Kidney Int. 2008, 74, 158-169; (d) Yang, L. Li, X.; Wang, H. Nephrol. Dial. Transplant. 2007, 22, 445-456.

3. (a) Wu, P. L.; Su, G. C.; Wu, T. S. J. Nat. Prod. 2003, 66, 996-998; (b) Michl, J. Ingrouille, M. J.; Simmonds, M. S. J.; Heinrich, M. Nat. Prod. Rep. 2014, 31, 676693.

4. Chung, Y.-M.; Chang, F.-R.; Tseng, T.-F.; Hwang, T.-L.; Chen, L.-C.; Wu, S.-F.; Lee C.-L.; Lin, Z.-Y.; Chuang, L.-Y.; Su, J.-H.; Wu, Y.-C. Bioorg. Med. Chem. Lett. 2011 $21,1792-1794$

5. Wang, Q.; Kuang, H.; Su, Y.; Sun, Y.; Feng, J.; Guo, R.; Chan, K. J. Ethnopharmacol. 2013, 146, 9-39.

6. Margrey, K. M.; Hazzard, A. D.; Scheerer, J. R. Org. Lett. 2014, 16, 904-907.

7. Selected reviews on bioactive pyridones: (a) Wall, M. E. Med. Res. Rev. 1998, 18 299-314; (b) Mitscher, L. A. Chem. Rev. 2005, 105, 559-592; (c) Tun, M. K. M. Herzon, S. B. J. Exp. Pharm. 2005, 4, 113-123; (d) Torres, M.; Gil, S.; Parra, M. Curr. Org. Chem. 2005, 9, 1757-1779; (e) Pommier, Y. Nat. Rev. Cancer 2006, 6 789-802; (f) Thompson, P.; Manganiello, V. C.; Degerman, E. Curr. Top. Med Chem. 2007, 7, 421-436; (g) Jessen, H. J.; Gademann, K. Nat. Prod. Rep. 2010, 27 1168-1185; (h) Haga, A.; Tamoto, H.; Ishino, M.; Kimura, E.; Sugita, T.; Kinoshita, K.; Takahashi, K.; Shiro, M.; Koyama, K. J. Nat. Prod. 2013, 76, 750 754.

8. Diketopiperazine $\mathbf{6}$ can be prepared in 4 steps from glycine methyl ester in 55\% overall yield. See Ref. 6 .

9. For the first reports concerning isomerization (and equilibrium) of related alkylidene DKP structures, see: (a) Porter, A. E. A.; Sammes, P. G. J. Chem. Soc. (C) 1970, 2530 [single page article]; (b) Machin, P. J.; Porter, A. E. A.; Sammes, P. G. J. Chem. Soc., Perkin Trans. 1 1970, 404-409.

10. Danishefsky, S.; Prisbylla, M. P.; Hiner, S. J. Am. Chem. Soc. 1978, 100, 2918 2920. 